(C) Dereito Vol.27, nºEXT:111-136 (Xaneiro-Decembro, 2018) • ISSN 1132-9947

\title{
LA PUBLICIDAD ACTIVA EN LA LEGISLACIÓN ESTATAL Y GALLEGA DE TRANSPARENCIA
}

Active advertising in state and galician transparency legislation

DOI: http://dx.doi.org/10.15304/dereito.27.Ext.5788

JosÉ JULIO FERnÁNDEZ RODRÍGUEZ

Profesor Titular de Derecho Constitucional

Universidade de Santiago de Compostela

josejul.fernandez@usc.es

ANa MARÍa Gude FERnÁndez

Profesora Titular de Derecho Constitucional

Universidade de Santiago de Compostela

ana.gude@usc.es

\section{Resumen}

El trabajo hace un análisis de la publicidad activa en la LGT, en conexión con la norma básica (LETAI), lo que exige examinar críticamente cuestiones tales como los principios de publicidad activa, al información que debe publicarse, el portal de transparencia y las garantías. Asimismo, se realizan valoraciones prospectivas sobre cómo debe evolucionar esta cuestión.

Palabras clave: publicidad activa, principios de publicidad activa, información que debe publicarse, portal de transparencia, garantías.

\section{Abstract}

The work makes an analysis of active advertising in the LGT, in connection with the basic standard (LETAI), which requires critically examining issues such as the principles of active advertising, the information to be published, the transparency portal and the guarantees. Likewise, prospective assessments are made on how this issue should evolve.

Keywords: active advertising, active advertising principles, information to be published, transparency portal, guarantees

\section{SUMARIO}

1. INTRODUCCIÓN.;- 2. LOS PRINCIPIOS GENERALES: 2.1. La condición genérica de la información sujeta a publicidad. 2.2. Las características de la información publicada.;- 2.3. La complementariedad autonómica.;- 2.4. Referencia a los límites.;- 2.5. Las sedes electrónicas y las webs.;- 3. LA INFORMACIÓN QUE DEBE PUBLICARSE: 3.1. Información institucional, organizativa y de planificación. 3.2. Información de relevancia jurídica.;3.3. Información económica, presupuestaria y estadística: 3.3.1. Contratos.;- 3.3.2. Convenios y encomiendas de gestión.;- 3.3.3. Subvenciones y ayudas públicas.;- 3.3.4. Los presupuestos y el estado de ejecución.;- 3.3.5. Cuentas anuales.;- 3.3.6. Información referida a los 
altos cargos y personal de designación política.;- 3.3.7. Información estadística sobre el cumplimiento y calidad de los servicios públicos.;3.3.8. Las declaraciones anuales de bienes y actividades de los representantes locales.;- 3.3.9 Relación de los bienes inmuebles que sean de su propiedad o sobre los que ostenten algún derecho real.;- 3.4. Referencia adicional a la LGT. 4. GARANTÍAS.;- 5. EL PORTAL DE TRANSPARENCIA.;- 6. MIRADA AL FUTURO.;- 7. CONCLUSIONES.;- 8. BIBLIOGRAFÍA.

\section{INTRODUCCIÓN}

La publicidad activa es uno de los elementos esenciales de la regulación de la transparencia. Es el que aporta un aspecto objetivo a la misma, lo que configura una dimensión que va más allá de las cuestiones subjetivas del acceso a la información.

La doctrina ha puesto de manifiesto esta especial relevancia de la publicidad activa en el tema de la transparencia de la actividad pública. Así, se ha dicho que es "la gran tendencia revolucionaria en materia de transparencia y acceso a la información, fundamentalmente de la mano de Internet"1 , o que se trata de las "obligaciones más novedosas en materia de transparencia" ${ }^{2}$. Sin duda, la publicidad activa implica un cambio de paradigma en el funcionamiento del poder, pues de una idiosincrasia reactiva (ante las solicitudes de acceso a la información) se pasa a un posicionamiento proactivo ( $\mathrm{si}$, claro está, se cumple debidamente con el contenido que exige esta publicidad activa). Incluso, podría hablarse de un cambio de cultura en la visión que el poder tiene de la ciudadanía, asumiéndose un rol colaborador y facilitador de la participación. Las posibles tendencias de futuro en este tema, que comentamos más abajo, seguramente incidan en esta línea.

Por publicidad activa entendemos el conjunto de información que los sujetos sometidos a la legislación de transparencia deben ofrecer motu proprio a través de una ubicación específica para ella, que en líneas generales puede denominarse portal de transparencia (de la entidad de que se trate). En este sentido se expresa Cotino cuando indica que "los sujetos obligados por la Ley de Transparencia tienen que suministrar información sin esperar a que nadie la solicite" ${ }^{\prime 3}$. Estamos, por lo tanto, ante concretas obligaciones que las entidades sujetas deben cumplir en lo referente a la difusión de diversa información. En todo caso, téngase en cuenta que este trabajo debe completarse con el artículo que también consta en esta revista sobre el ámbito subjetivo de aplicación de la

\footnotetext{
${ }^{1}$ C. BARRERO, E. GUICHOT y C. HORGUÉ, "Publicidad activa", en E. GUICHOT (coord.), Transparencia, acceso a la información pública y buen gobierno. Estudio de la ley 19/2013, de 9 de diciembre, Tecnos, Madrid, 2014, p. 143.

2 M. J. GARCÍA MORALES, Transparencia y rendición de cuentas de las relaciones de cooperación intergubernamental en el Estado autonómico, Generalitat de Catalunya, Barcelona, 2017, p. 80.

3 L. COTINO, "España" en VV. AA., Transparencia e información pública, Federación Iberoamericana de Ombudsman, Madrid, 2015, p. 238.
} 
normativa de transparencia, para conocer los detalles sobre estas entidades sujetas.

Tanto la LGT como la LETAI establecen los principios generales en este tema de la publicidad activa y la información que debe publicarse en las correspondientes sedes electrónicas, organizando dicha información por su tipología (en lo que es más prolija la ley gallega). Ambas leyes dedican un capítulo a la publicidad activa, que se ubica tras otro dedicado al "ámbito subjetivo de aplicación" de la transparencia de la actividad pública. En concreto la ley gallega destina el Capítulo II del Título I a esta cuestión, siguiendo, así, la estructura de la ley estatal. Se fija, de este modo, qué hay que publicar, dónde y cómo. Veámoslo

\section{LOS PRINCIPIOS GENERALES}

Como hemos dicho, existe una regulación específica de los principios generales que rigen en la publicidad activa. Dichos principios establecen cómo ha de publicarse la información, con qué características y cualidades. Las similitudes entre la legislación autonómica gallega y la estatal en este aspecto son de nuevo evidentes.

Por lo tanto, tenemos unos principios que rigen uno de los contenidos del también principio de transparencia. Este aparece como un macroprincipio con un contenido diverso, que incluye igualmente principios y derechos ${ }^{4}$. En este sentido, el art. 6 LGT, bajo el rótulo de "principios generales", contiene cinco apartados que recogen un conjunto de previsiones de relevancia.

\subsection{La condición genérica de la información sujeta a publicidad}

La finalidad de esta publicación se muestra de manera explícita: el fomento del ejercicio por parte de la ciudadanía "de su derecho fundamental a la participación y al control sobre los asuntos públicos" (también art. 6.1 LGT). La Ley estatal también es aquí un tanto más comedida: la información se publica por su relevancia para garantizar la transparencia de la actividad "relacionada con el funcionamiento y control de la actividad pública" (art. 5.1 LETAI).

Por lo tanto, la información sujeta a esta obligación de publicidad tiene un aspecto nuclear genérico y finalista, en tanto que es la información que permitirá a las personas participar en el sistema democrático. Ello debería ser objeto de una interpretación extensiva.

\footnotetext{
${ }^{4}$ No es este el momento de hacer un análisis de teoría de las normas jurídicas, pero sí semeja oportuno recordar que un principio es una norma que persigue una vigencia general que lleva a la abstracción en cuanto a la exigencia de actividad ulterior. Este rasgo permite una gradación de su cumplimiento. Los principios buscan ser tenidos en cuenta siempre, ser aplicados de forma abierta por los operadores jurídicos. Establecer un principio (transparencia) que contiene dentro de sí derechos (acceso) no parece una construcción rigurosa, salvo que estimemos que aquel "principio" no lo es realmente en sentido jurídico. Sobre esto también reflexionamos en el artículo que consta en esta revista sobre las motivaciones y bases epistemológicas.
} 


\subsection{Las características de la información publicada}

Otra serie de cuestiones se refieren a las características específicas que se exigen de la información que se publica. A ello se dedican el apartado 1 y el 5 del art. 6 LGT.

Así, se establece que la información se publique "de forma periódica, actualizada, clara, veraz, objetiva y fácilmente accesible" (art. 6.1 LGT). La ley estatal resulta más parca y alude a publicación "de forma periódica y actualizada" (art. 5.1 LETAI). Estos adjetivos deben interpretarse en un sentido común. De este modo, por publicación periódica hay que entender la que se repite en el tiempo, con cierta regularidad, siendo lo deseable que se haga cuando haya datos e informaciones que deberían publicarse, sin dilaciones que retrasen esa subida de información. A su vez, lo actual es lo que está puesto al día y se corresponde con la realidad del momento en el que se consulta. La información resulta clara cuando se muestra sencilla de comprender, o sea, inteligible. Lo veraz es lo que se ajusta a la verdad o a la realidad. La información objetiva es la que corresponde con su propio contenido, sin verse alterada o manipulada por ciertas maneras de pensar o de interpretar. Y, por su parte, la accesibilidad se presenta como uno de los conceptos claves en el mundo digital, pues de poco sirve que los datos cumplan las características anteriores si luego no resultan accesibles. Lo accesible es aquello a donde se llega con facilidad. En la práctica debería traducirse en un reducido número de clics en la web para llegar a la información que se pretende. Tal vez no más de tres. También lo accesible, en otro sentido, es aquello que resulta de fácil comprensión.

A partir de estas ideas sencillas aparecen un elevado número de consecuencias que a veces requieren complejos procedimientos para afrontarlas. Más allá de las características físicas o cognitivas de la persona, la accesibilidad busca que tal persona pueda llegar a la información, entenderla y usarla. En este sentido, en el ámbito informático, se crean distintas herramientas, como lupas de redimensionamiento de contenido web, comandos de voz, generadores de subtítulos, tramas o diseños, etc. Los supuestos más relevantes son los que se refieren a las personas con discapacidad, respecto a las cuales hay que defender un verdadero derecho de accesibilidad que le permita construir una verdadera autonomía e independencia ${ }^{5}$.

Completando estas previsiones del art. 6.1, la LGT aborda temas similares en el art. 6.5, como también hace la LETAI en el art. 5.5. De este modo se indica que "toda la información será comprensible, de acceso fácil y gratuito". Lo "comprensible" y el "acceso fácil" son ideas que la ley ya había reflejado en el citado art. 6.1. Se insiste en la misma línea: la información que se sube debe ser entendible, y se tiene que llegar a ella sin gran esfuerzo. Se trata, por lo tanto, de eliminar barreras que dificulten la consulta de la información. $Y$ en este orden de

\footnotetext{
${ }^{5}$ Sobre el modelo social con el que se debe analizar las cuestiones de discapacidad, puede verse J. J. FERNÁNDEZ RODRÍGUEZ, "'La reconfiguración del derecho a la educación de las personas con discapacidad", Fundamentos. Cuadernos monográficos de teoría de la constitución e historia constitucional, Universidad de Oviedo, núm. 7, 2017, pp. 393-424.
} 
consideraciones ahora se ofrece una cualidad a mayores, la gratuidad. Se trata de un elemento relevante, que impide que el acceso conlleve una exigencia de contraprestación económica.

Por último, se especifica la característica de la accesibilidad a la que se había referido antes la ley, y nosotros. En concreto la atención se presta a las personas con discapacidad, con el siguiente tenor en Galicia y el Estado: la información "estará a disposición de las personas con discapacidad en una modalidad suministrada por medios o en formatos adecuados de manera que resulten accesibles y comprensibles, conforme al principio de accesibilidad universal y diseño para todos y todas". Como dijimos supra, se trata de una cuestión crucial para asegurar una auténtica autonomía e independencia a estas personas.

\subsection{La complementariedad autonómica}

El art. 6.2 de la LGT se ubica en la clave competencial propia del Estado Autonómico. Se prevé que las obligaciones de publicidad activa de la ley gallega son complementarias de las previstas en la normativa básica estatal, como no podía ser de otro modo si estamos ante legislación básica. Asimismo, y desde una óptica amplificadora, se matiza que podrían aplicarse "otras disposiciones específicas que prevean un régimen más amplio en materia de publicidad". Esta es una formulación copiada de la ley estatal (art. 5.2), que también cita la posible aplicación de la normativa autonómica correspondiente.

\subsection{Referencia a los límites}

En el art. 6.3 LGT se alude a la cuestión de los límites en la publicidad activa. En primer lugar establece que serán de aplicación los límites del derecho de acceso a la información pública previstos en la normativa estatal básica. En este sentido, el art. 5.3 LETAI se refiere a los límites previstos en los arts. 14 y 15 de dicha ley estatal. El art. 14 LETAI es un precepto criticado por elevado número de límites que fija, claramente desproporcionados en su conjunto: seguridad nacional; defensa; relaciones exteriores; seguridad pública; la prevención; investigación y sanción de los ilícitos penales, administrativos o disciplinarios; la igualdad de las partes en los procesos judiciales y la tutela judicial efectiva; las funciones administrativas de vigilancia, inspección y control; los intereses económicos y comerciales; la política económica y monetaria; el secreto profesional y la propiedad intelectual e industrial; la garantía de la confidencialidad o el secreto requerido en procesos de toma de decisión; la protección del medio ambiente. Con un elenco así, semeja fácil, si se quiere, encontrar una disculpa para no ofrecer la información. Por su parte, el art. 15 LETAI se dedica al tema de protección de datos, diferenciando casos: datos especialmente protegidos; datos meramente identificativos de la organización, funcionamiento o actividad del órgano; ponderación cuando no existan datos especialmente protegidos.

Aunque la ley estatal ya alude a la protección de datos, la ley gallega insiste en que son de aplicación los límites "derivados de la normativa en materia de protección de datos". No cabe duda de que este es un conflicto 
llamado a ser cotidiano. Incluso, se puede afirmar que la clave de un eficaz funcionamiento de la normativa será lograr un adecuado equilibrio entre el principio de transparencia y el derecho a la protección de datos, basado en la razonabilidad y en la proporcionalidad. Las leyes que estamos analizando ponen un ejemplo para resolver un tipo de estos conflictos y, así, se establece que cuando la información contenga "datos especialmente protegidos", la publicidad "solo se llevará a cabo previa disociados de los mismos" (en la parte final de los citados arts. 6.3 LGT y 5.3 LETAI). Téngase en cuenta que el proceso de disociación es aquel en el que se separa la información identificatoria de la personas titulares de los datos y el resto del contenido de la misma. El dato disociado no permitirá la identificación del afectado ${ }^{6}$.

Con relación a lo que estamos comentando, en la práctica pueden producirse desajustes, pues ante una duda interpretativa el órgano público optará por no publicar ya que la normativa de protección de datos es más exigente que la de transparencia en el terreno de las sanciones ${ }^{7}$. Por ello, hay que reclamar una especial formación de los decisores públicos en búsqueda de un adecuado equilibrio. Asimismo, conviene que tales decisores también estén imbuidos por la cultura de la transparencia para que se pueda existir cierto contrapeso en la ponderación. Además, consideramos que, desde un punto de vista hermenéutico, habría que ser restrictivos en la interpretación de los límites a la publicidad activa.

Sea como fuere, el Criterio Interpretativo 2/2015, de la Agencia Española de Protección de Datos y del Consejo de Transparencia y Buen Gobierno, indica que los límites del art. 14 LETAI "podrán" ser aplicados (o sea, no se aplican directamente ni en todo caso) y que dichos límites no operan automáticamente. Lo que significa que este art. 14 LETAI en ningún caso supone "exclusión automática del derecho a la información, antes al contrario deberá justificar(se) el test del daño y el del interés público para ser aplicado".

\subsection{Las sedes electrónicas y las webs}

También en este precepto relativo a los principios generales en publicidad activa, se fija la obligación de publicar la información en "las correspondientes sedes electrónicas o páginas web" (art. 6.4 LGT, y art. 5.4 LETAI). La diferencia entre unas y otras no resulta baladí ya que las

\footnotetext{
${ }^{6}$ La Ley Orgánica 15/1999, de protección de datos de carácter personal, entiende por procedimiento de disociación "todo tratamiento de datos personales de modo que la información que se obtenga no pueda asociarse a persona identificada o identificable" (art. 3.f LOPD).

7 Los casos jurisprudenciales más conocidos suelen inclinarse por limitar el acceso. Así, por ejemplo, la Sentencia del Tribunal Supremo de 9 de marzo de 2015 (rec. 3552/2012) apoya una resolución sancionadora de la Agencia Española de Protección de Datos por infringir el deber de secreto la Consellería de Presidencia, Administración e Xustiza de la Xunta de Galicia. La Xunta había publicado una lista de admitidos a unas ayudas para personas con discapacidad, en la que recogía apellidos, nombres de los solicitantes y de las personas discapacitadas objeto de la ayuda. Aquí parece clara la infracción del deber de secreto que sanciona la Agencia.
} 
sedes electrónicas pueden exigir una identificación para entrar en ellas ${ }^{8}$, mientras que las páginas webs en principio están en abierto. De todos modos, parece más conveniente interpretar que la opción de la sede electrónica no debería exigir en todo caso identificarse para acceder a la información ligada a la publicidad activa. Lo que sí está claro es que, como ya afirmamos en otro lugar, la tecnología digital ha jugado un rol facilitador y transcendental en el afianzamiento del principio de transparencia ${ }^{9}$.

Pues bien, la normativa citada establece algunas de las características y rasgos de dichas sedes electrónicas y webs y de la forma en cómo deben alojar la información.

Por un lado, esa información se publicará de modo "claro, estructurado, conciso y entendible". La claridad es una cualidad que la ley gallega repite, primero referida a la publicación en sí (el ya visto supra, art. 6.1 LGT), y ahora conectada con las sedes electrónicas. Hay que entender lo mismo, o sea, que la información se debe subir de manera comprensible para el ciudadano que la consulta. Acto seguido, la LGT aporta otros adjetivos: la publicación estructurada hace referencia a un orden y sistemática, que es de suponer ayuda a la consulta y a la localización de lo que se busca; la concisión alude a la economía de medios para expresarse, es decir, que el legislador gallego no quiere prolijidades, divagaciones ni circunloquios en las webs de transparencia; y la información entendible es un sinónimo de la información clara, pues también hace referencia a inteligible. La ley estatal se expresa igual, salvo en lo de publicación "clara", a lo que no alude (art. 5.4 LETAI). Igualmente se aboga por los formatos reutilizables, respecto a los cuales ambas leyes muestran preferencia. Este formato es el que permite al ciudadano que accede a la información pública volverla a emplear en un momento posterior. Puede ser algo tan fácil como usar un formato que permita la funcionalidad informática de cortar y pegar.

Por otro lado, se exige que se establezcan "mecanismos adecuados" para facilitar "la accesibilidad, interoperabilidad, calidad y reutilización de la información publicada, así como su identificación y localización". Ya hemos visto la cuestión de la accesibilidad referida a la información en sí; ahora se vuelve sobre ella para reclamarla del portal web. Por su parte, la interoperabilidad es la capacidad y característica de un sistema para compartir datos e intercambiar información ${ }^{10}$. La calidad de la información publicada es una exigencia que se conecta con el servicio efectivo a la

\footnotetext{
${ }^{8}$ El art. 10 de la Ley estatal 11/2007, de acceso electrónico de los ciudadanos a los servicios públicos, regula las sedes electrónicas; y el art. 13 aborda las formas de identificación y autentificación.

9 J. J. FERNÁNDEZ RODRÍGUEZ y D. NEIRA BARRAL, "El papel de las defensorías del pueblo en España en el control de la transparencia y el acceso a la información", Revista Estado, Gobierno y Gestión Pública, Universidad de Chile, núm. 27, 2016, p. 92.

10 El Esquema Nacional de Interoperabilidad fue aprobado por el Decreto 4/2010. La Resolución de 19 de febrero de 2013, de la Secretaría de Estado de Administraciones Públicas, aprueba la Norma Técnica de Interoperabilidad de Reutilización de recursos de información.
} 
participación ciudadana y al control de los asuntos públicos. Si la información es de calidad, permitirá llevar a cabo tal control; si no lo es, por ser banal o fútil, anecdótica o de adorno, no se podrá efectuar el control, y se resquebrajará, ni más ni menos, la calidad democrática del sistema. La identificación es la posibilidad de detectar realmente lo que se persigue, de reconocer el dato que se busca. Esta identificación exige rótulos, apartados, subapartados o estrategias organizativas similares para facilitar la tarea al ciudadano que accede a la web de transparencia. En fin, la localización es la cualidad de la información y de la web que permite al ciudadano hallar lo que investiga.

En el tema de la reutilización de la información de la información del sector público es de obligada cita la Ley estatal 37/2007, que presenta en su mayor parte carácter básico al amparo del art. $149.1 .18^{a}$ de la Constitución. En virtud del art. 3 de esta Ley estatal 37/2007 "se entiende por reutilización el uso de documentos que obran en poder de las Administraciones y organismos del sector público, por personas físicas o jurídicas, con fines comerciales o no comerciales, siempre que dicho uso no constituya una actividad administrativa pública"11.

En la ley estatal se prevé una cuestión más en el citado art. 5.4 LETAI, pensada para evitar sobrecargas en ciertas entidades. Así, la Administración Pública pondrá medios electrónicos para cumplir las obligaciones de esa ley a disposición de las entidades sin ánimo de lucro, con fines exclusivamente de interés social o cultural, y presupuesto inferior a 50.000 euros. La concreta Administración Pública que está sujeta a esta obligación es aquella de la que provenga "la mayor parte de las ayudas o subvenciones públicas percibidas". Esta previsión es básica, por lo que se extiende a las comunidades autónomas.

\section{PUBLICIDAD ACTIVA}

La categoría de publicidad activa implica un deber para todas las entidades sujetas a la normativa de difundir de forma periódica y actualizada la información cuyo conocimiento sea relevante para garantizar la transparencia de su actividad. Así se podrá ejercer el control por parte de la ciudadanía y se posibilitará su participación real en los asuntos públicos.

La publicidad activa ha sido concebida como un derecho de los administrados a disponer de una cierta información que es de obligada publicación para una serie de sujetos, y como una obligación de proporcionarla de oficio, sin necesidad del requerimiento de dichos administrados. El legislador busca a través de la publicidad activa dotar a la transparencia de operatividad, más allá de reconocerla como un valor o principio de actuación, para convertirla así en un imperativo legal con la estructura de derecho/obligación. Esta transformación confirma el nuevo posicionamiento del administrado en su relación con la Administración

${ }^{11}$ Esta ley fue desarrollada por el Real Decreto 1495/2011. 
respecto al derecho a la información, en el que pasa a ser sujeto activo de la acción pública, mediante una participación más intensa en ella ${ }^{12}$.

Tanto la LETAI como la LGT dedican una seria de artículos a fijar la información que debe publicarse. El análisis que realizamos a continuación parte de la LETAI, por ser la norma básica, a la que iremos añadiendo referencias de la LGT, más extensa y detallada en esta cuestión. El listado de los arts. 6 a 8 de la LETAI es de mínimos, de información que el propio legislador estatal de 2013 ha considerado importante, que debe ("publicarán") ampliarse, y nunca reducirse, a toda materia que se juzgue relevante para el conocimiento público, siempre dentro del respeto de los límites establecidos en la propia norma.

Tres son los bloques de materias, según la LETAI, sobre los que recae esta obligación de publicidad activa: la información institucional, organizativa y de planificación (art. 6), la información de relevancia jurídica (art. 7) y la información económica, presupuestaria y estadística (art. 8). Dependiendo del bloque temático el deber de publicidad recae sobre un mayor o menor número de sujetos.

\subsection{Información institucional, organizativa y de planificación}

Las obligaciones de publicidad activa previstas en el artículo 6 LETAI no afectan por igual a todos los sujetos destinatarios de la norma. Las establecidas en el apartado primero, es decir, la publicación de las funciones que desarrollan, la normativa que les afecta y la estructura organizativa se imponen con carácter general, vinculan a las Administraciones Públicas, a las instancias y entidades recogidas en el artículo 2.1 de la LETAI, así como también a esos "otros sujetos obligados" definidos en el artículo 3: los partidos políticos, las organizaciones sindicales y empresariales y las entidades privadas financiadas con fondos públicos en las cuantías dispuestas en el precepto. Por el contrario, los deberes descritos en el apartado segundo, esto es, los referidos a la difusión de los planes y programas, actividades, medios y tiempo para acometerlos así como el grado de cumplimiento y resultados, afectan únicamente a las Administraciones Públicas.

La publicación de las funciones exige un conocimiento detallado del organigrama de cada institución junto con la entidad, perfil y trayectoria profesional de los responsables de los distintos órganos, departamentos y áreas, sin requerir el dar a conocer su retribución. Asimismo, se ha de difundir toda aquella normativa que sea de aplicación a los sujetos comprendidos en el ámbito de aplicación del deber de publicidad activa: no basta con el mero enunciado sino que es preciso plasmar su contenido colgándolo en la web o sede electrónica. Por otro lado, es preciso indicar que por "normativa" se ha de entender no solo las leyes o los reglamentos de todo tipo sino también los decretos y las órdenes ministeriales, es decir, toda disposición que regule y fije las pautas de actuación.

\footnotetext{
12 M. Ma. LAFUENTE BENACHES, "Publicidad activa y medios propios de la Administración pública" en Revista General de Derecho Administrativo, no 45, 2017. En http://www.iustel.com/v2/revistas/detalle_revista.asp?id=1\&numero $=45$
} 
Durante la tramitación de la ley estatal uno de los asuntos más debatidos fue el de si deberían o no ser objeto de conocimiento público las agendas de reuniones de los altos cargos, pensando concretamente en los lobbies. La ausencia de igualdad política es uno de los problemas más importantes de las democracias contemporáneas, en las que la presencia de grupos de interés muy poderosos y sus correspondientes lobbies pueden desequilibrar profundamente la toma de decisiones y generar un sistema político que favorezca repetidamente a los mejor organizados y con más medios, y que perjudique, a menudo, a la ciudadanía en general. Por ello, la incorporación de la agenda de los actores públicos más relevantes a las obligaciones de transparencia y el relato de sus reuniones con grupos de interés podría haber sido una interesante novedad de la ley. La doctrina considera que una adecuada redacción de estas obligaciones hubiera exigido que parte de este epígrafe se aplicase también al poder legislativo "pues el seguimiento de la denominada huella legislativa no se queda en el ejecutivo, sino que su rastreo en el ámbito legislativo también es importante, incluso en España, donde la disciplina parlamentaria hace más innecesario acudir a los diputados y senadores para buscar redacciones que se adecuen a los intereses de los lobbies correspondientes" ${ }^{\prime 13}$.

La LGT ha incorporado a la lista de materias a nivel estatal que deben ser objeto de publicidad activa las siguientes: las agendas de la actividad institucional pública de los miembros de la Xunta de Galicia y de las personas que ocupan altos cargos, las competencias de los distintos órganos y entidades, los traspasos de funciones y servicios, las delegaciones de competencias, la localización de las unidades administrativas, los medios de contacto y horario de atención al público, los códigos éticos o de buen gobierno, los estándares de buenas prácticas y responsabilidad social aplicables, y, por último, el contenido del Registro de Entidades del Sector Público de la Comunidad Autónoma de Galicia.

\subsection{Información de relevancia jurídica}

Se trata de una obligación de publicidad activa que incumbe exclusivamente a las Administraciones Públicas pues solo ellas generan información de esta naturaleza. El acceso a la información de relevancia jurídica, siempre que permita la colaboración de los ciudadanos en su elaboración normativa facilitando su acceso a los cauces de participación, constituye un importante avance dentro de nuestra democracia. Dar a conocer una norma sin que se pueda intervenir o participar en el proceso carece de sentido y deslegitima a los poderes públicos ${ }^{14}$.

El artículo 7 de la norma estatal de transparencia dispone que han de hacerse públicas, en primer lugar, las directrices, instrucciones, circulares, acuerdos o respuestas a consultas particulares de otros órganos cuando

13 M. VILLORIA MENDIETA, "La publicidad activa en la ley de transparencia, acceso a la información y buen gobierno: posibilidades e insuficiencias". En http://exteriors.gencat.cat/web/.content/transparencia/publicacions/gov_obert1/governo bert_1_es.pdf, págs. 24-25.

${ }^{14}$ M. VILLORIA MENDIETA, "La publicidad activa...", op. cit., pág. 26. 
supongan una interpretación del Derecho o tengan efectos jurídicos. A nivel autonómico la ley gallega prevé, en el artículo 9 b), que también han de darse a conocer, las resoluciones judiciales firmes que afecten a la vigencia o interpretación de las normas dictadas por la Administración pública competente.

Son también objeto de publicidad, en segundo lugar, según el art. 7 b) de la LETAI, los anteproyectos de ley y proyectos de decretos legislativos en el momento en el que se soliciten los dictámenes a los órganos consultivos correspondientes. Los proyectos de decretos legislativos inicialmente no se incorporaron al texto del Anteproyecto de Ley sino que fue tras el dictamen del Consejo de Estado en donde se advirtió su ausencia y se señaló que no existía ninguna razón lógica para omitirlos. Los decretosleyes, en cambio, no se incluyeron, por su carácter de urgentes y por su propia naturaleza. En el caso de que no sea exigible el dictamen de los órganos consultivos tanto para los anteproyectos de ley como para los proyectos de decretos legislativos la publicación se realizará en el momento de su aprobación. La LGT reitera, en el artículo $9 \mathrm{c}$ ), esta obligación de difundir el texto normativo pero lo sitúa en una fase previa a la estatal, a partir del momento en el que se produce la aprobación tanto si se trata de anteproyectos de ley como de disposiciones administrativas. En tercer lugar, y por lo que se refiere a los proyectos de reglamentos, la LETAI obliga a que el requisito de ofrecer información pública se cumpla cuando se soliciten los dictámenes, esto es, una vez que hayan sido requeridos a los órganos consultivos correspondientes. La norma emplea un criterio diferente al previsto para los anteproyectos de ley y proyectos de decretos legislativos y tampoco deja muy claro si la publicidad tiene que producirse de manera simultánea a la solicitud del dictamen o con posterioridad. Se trata de una cuestión que, como ha señalado la doctrina, parece lógico que debiera aclararse cuanto antes aunque lo más conveniente sería elegir la primera opción en aras a la obtención de una mayor transparencia ${ }^{15}$.

En cuarto lugar, es preciso dar a conocer las memorias e informes que integren los expedientes de elaboración de textos normativos. No está claro si los informes jurídicos, dictámenes de órganos consultivos, notas o informes internos, actas o minutas de las reuniones de los comités y grupos de trabajo, así como los informes, pareceres externos y borradores de textos normativos deben ser objeto de publicación. Tampoco aclara el artículo 7.d), a diferencia de lo que se prevé el apartado anterior y aún cuando esta carencia fue advertida por el Consejo de Estado, el momento en el que se ha de cumplir con esta obligación en los casos en los que en el procedimiento de elaboración de la norma no es exigible el dictamen del órgano consultivo.

En este supuesto de hacer públicas memorias e informes de los expedientes de elaboración de textos normativos, se cita expresamente la "memoria del análisis de impacto normativo", regulada por el Real Decreto $1.083 / 2009$, de 3 de julio. Este documento es la principal novedad que se

${ }^{15}$ M. VILLORIA MENDIETA, "La publicidad activa...", op. cit., pág. 28. 
introduce por la LETAI en este ámbito. Se trata de un documento único en el que se han de integrar "las memorias, estudios e informes" exigidos en el procedimiento de elaboración de las normas estatales ${ }^{16}$. En cualquier caso, es preciso señalar que el artículo 7.d) exige la publicación de todas "las memorias e informes que conformen el expediente", incluidos, por tanto, los de carácter preceptivo, es decir los del Consejo de Estado u órgano consultivo autonómico.

Por último, han de publicarse los documentos que, de acuerdo con la legislación sectorial vigente, "tengan que ser sometidos a un período de información pública" [art. 7.e)]. Se establece este deber al servicio de un trámite fundamental del procedimiento administrativo como es el de información pública. Esta previsión ha sido calificada de manera favorable por la doctrina en la medida que la publicación en las sedes electrónicas o páginas web de una información de las características de la dispuesta en esta LETAI, "clara, estructurada y entendible para los interesados" ha de tener, sin duda, un valor extraordinario para el conocimiento de los datos que sirven de base a la actuación administrativa así como del contenido de sus decisiones, requisito fundamental para que el trámite de audiencia cumpla con su función ${ }^{17}$.

\subsection{Información económica, presupuestaria y estadística}

La categoría referida a la información económica, presupuestaria y estadística, regulada en el artículo 8 LETAI, es la más compleja de la llamada publicidad activa, y la de más importancia para la lucha contra la corrupción ${ }^{18}$. Se trata básicamente de materias de contenido económico y presupuestario, que tienen que ver con la disposición de los fondos públicos o versan sobre la situación económica de los responsables de la gestión pública, y por tanto constituyen un ámbito de especial interés para los ciudadanos. Conocer a qué actividades se destinan los fondos públicos y si la gestión administrativa con repercusión económica o presupuestaria

\footnotetext{
${ }^{16}$ El artículo 2.1 de este Real Decreto 1.03/2009 describe su contenido: "a) oportunidad de la propuesta; $b$ ) contenido y análisis jurídico, que incluirá el listado pormenorizado de las normas que quedarán derogadas como consecuencia de la entrada en vigor de la norma; c) análisis sobre la adecuación de la norma propuesta al orden de distribución de competencias; d) impacto económico y presupuestario, que comprenderá el impacto sobre los sectores, colectivos o agentes afectados por la norma, incluido el efecto sobre la competencia, así como la detección y medición de las cargas administrativas; e) impacto por razón de género: se analizarán y valorarán los resultados que se pueden seguir de la aprobación del proyecto desde la perspectiva de la eliminación de desigualdades y de su contribución a la consecución de los objetivos de igualdad de oportunidades y de trato entre mujeres y hombres, a partir de los indicadores de situación de partida, de previsión de resultados y de previsión de impacto recogidos en la Guía Metodológica a que se refiere la disposición adicional primera". Junto a ello, podrá incluir, como prevé el apartado segundo del precepto, "cualquier otro extremo que pudiera ser relevante a criterio del órgano proponente, prestando especial atención a los impactos de carácter social y medioambiental y al impacto en materia de igualdad de oportunidades, no discriminación y accesibilidad universal de las personas con discapacidad".

${ }^{17}$ C. BARRERO, E. GUICHOT y C. HORGUÉ, "Publicidad activa", op. cit., p. 172.

18 M. VILLORIA MENDIETA, "La publicidad activa ...", op. cit., pág. 30.
} 
ha sido eficiente y eficaz es información relevante. No existe ningún género de dudas, las palabras de Barrero, Guichot y Horgué son explícitas: "casos de mala disposición de fondos públicos, casos de corrupción o de privilegios encubiertos y pagados por todos deben evitarse" ${ }^{19}$. Según ellos, la transparencia se convierte en una medida de prevención o disuasión de actuaciones poco convenientes y, desde luego, en un medio o instrumento necesario para un control de la gestión pública por parte de la ciudadanía. Estamos, por lo tanto, ante claras medidas que sirven a la higiene en la vida pública.

La obligación de publicidad activa en esta materia corresponde, con carácter general, a todos los sujetos incluidos en el ámbito subjetivo de la LETAI con la salvedad de los partidos políticos, organizaciones sindicales, organizaciones empresariales y entidades privadas que reciban fondos públicos en la cuantía delimitada por el legislador, en cuyo caso la obligación se restringe a dar a conocer los contratos y convenios que celebren con las Administraciones Públicas y las subvenciones que provengan de éstas. De ahí que también las sociedades mercantiles participadas se encuentran entre los sujetos obligados a suministrar dicha información.

El art. 8 LETAI recoge la información que debe hacerse pública, "como mínimo", relativa a los actos de gestión administrativa con repercusión económica o presupuestaria, que comentamos a continuación.

\subsubsection{Contratos}

El incremento de la transparencia en relación con la contratación del sector público ha sido uno de los principales objetivos desde el momento en que se hizo necesario elaborar una Ley de transparencia y acceso a la información. En la fase inicial de la tramitación de esta norma hubo un acuerdo unánime entre los partidos políticos de que la contratación pública debía ocupar un lugar destacado entre las materias de publicidad activa. Como hemos dicho, la obligación de la información relativa a la contratación solo es aplicable a los partidos políticos, organizaciones sindicales y organizaciones empresariales, así como a las entidades privadas señaladas en el artículo 3 LETAI cuando se trate de contratos celebrados con una Administración Pública.

Estas previsiones fueron un avance en su momento, pues la normativa de contratación de 2011 (Real Decreto Legislativo 3/2011), en vigor cuando se aprobó la LETAI, presentaba unas obligaciones de publicidad que se orientaban casi en exclusiva a garantizar la transparencia en el procedimiento y la adjudicación ${ }^{20}$.

${ }^{19}$ C. BARRERO, E. GUICHOT y C. HORGUÉ, "Publicidad activa", op. cit., p. 173.

${ }^{20}$ Una vez formalizado el contrato, y por tanto seleccionado el adjudicatario, esa legislación contractual no contenía medidas de publicidad general o de difusión respecto a las incidencias en su ejecución, de modo que si se modificaba, o prorrogaba, o se extinguía anticipadamente un contrato no tenía que hacerse público. La LETAI amplió así la transparencia en materia contractual porque obliga ahora a las entidades del sector público a dar a conocer de manera activa en las sedes electrónicas o páginas web los datos de las incidencias que puedan producirse durante su ejecución. Ahora, con la 
La publicidad activa afecta también a todos los contratos que realicen las entidades sujetas a la Ley, incluidos los menores, de no ser así una gran parte de la actividad contractual quedaría al margen de la publicidad ${ }^{21}$. De todos modos, se plantea la duda si la LETAI se refiere, sin embargo, solo a los contratos sujetos a la legislación de contratos del sector público y de esta forma se excluye a los contratos patrimoniales de las Administraciones públicas, como son por ejemplo, los contratos de compraventa, donación, permuta, arrendamiento y negocios jurídicos análogos (excluidos en el art. 9 de la Ley 9/2017, de contratos del sector público). Esta omisión ha sido criticada doctrinalmente porque lo adecuado hubiera sido aprovechar esta oportunidad legislativa para garantizar que pudieran conocerse estos actos de disposición que afectan al patrimonio de los entes públicos.

La normativa estatal de transparencia tampoco exige publicitar las variaciones de plazo o del precio del contrato, que sí se recogían en el anteproyecto por tratarse de modificaciones del contrato, ni lo referido a su extinción. Poder conocer el resultado "final" de la contratación pública permitiría acceder a una información completa de la gestión realizada en el ámbito de la contratación, y, en consecuencia, de la gestión de los recursos públicos que para estos fines se asignan ${ }^{22}$.

La LGT, dedica un artículo, el 13, a establecer las obligaciones específicas de publicidad activa en materia contractual cuyos destinatarios están previstos en el artículo 3.1.a), b) y d) de la norma gallega: sector público autonómico, universidades y entidades estatutarias. No se menciona a las corporaciones de derecho público que desarrollan su actividad exclusivamente en el ámbito territorial gallego, ni tampoco a los entes instrumentales con personalidad jurídica propia creados para satisfacer necesidades de interés general que no tengan carácter industrial o mercantil que no estén integrados en el sector público autonómico, sin tampoco explicitar la causa. El ámbito subjetivo de la norma gallega no coincide con el de la ley estatal de transparencia, y a su vez esta última emplea conceptos de "ámbito subjetivo" no homólogos a los previstos en la normativa de contratación pública, lo que puede generar numerosos problemas durante su aplicación. La LGT, sin embargo, introduce dos novedades que son claramente positivas: la primera consiste en la obligación de publicar "/a composición de las mesas de contratación, del comité de personas expertas $\mathrm{y} / \mathrm{o}$ de los organismos técnicos especializados que deban intervenir en el proceso de adjudicación", lo que sin duda permitirá detectar conflictos de interés e incompatibilidades. Y la segunda novedad, relativa a la obligación de publicar el informe que justifique la externalización de prestaciones incluidas en el catálogo de

nueva Ley 9/2017, de Contratos del Sector Público, que entró en vigor el 9 de marzo de 2018, se avanza en este tema de la publicidad, por ejemplo suprimiendo la aplicación por cuantía del procedimiento negociado sin publicidad (que se sustituye por un nuevo procedimiento "abierto simplificado", que en teoría no descuida la publicidad).

${ }^{21}$ C. BARRERO, E. GUICHOT y C. HORGUÉ, "Publicidad activa", op. cit., p. 177.

${ }^{22}$ C. BARRERO, E. GUICHOT y C. HORGUÉ, "Publicidad activa", op. cit., p. 179. 
autoprovisión regulado por el art. 8 de la Ley gallega 14/2013, de racionalización del sector público autonómico. Es ésta la única obligación innovadora de transparencia en materia de racionalización de la contratación ${ }^{23}$.

\subsubsection{Convenios y encomiendas de gestión}

Los convenios y encomiendas de gestión se encuentran vinculados de forma directa con los contratos. Las organizaciones públicas para prestar servicios o realizar negocios jurídicos acuden en muchas ocasiones a estas figuras, que suponen casi siempre un elevado compromiso de recursos públicos, por eso, lógicamente la LETAI ha previsto su publicidad.

EL artículo 8.1.b) LETAI en su primer párrafo obliga a publicar "la relación de los convenios suscritos, con mención de las partes firmantes, su objeto, plazo de duración, modificaciones realizadas, obligados a la realización de las prestaciones y, en su caso, las obligaciones económicas convenidas". Por su parte, la LGT, siguiendo su tónica habitual, es todavía más rigurosa y exige en su artículo 15.2 que cada consejería o entidad habrá de remitir para su publicación en el Diario Oficial de Galicia, dentro de los primeros veinte días de los meses de enero, mayo y septiembre de cada año, una relación de los convenios suscritos referida al cuatrimestre anterior. El texto del convenio tendrá que incluir la correspondiente memoria en la que se justifique la utilización de esta figura. Si dichos convenios implican obligaciones económicas para la Hacienda autonómica o para las entidades públicas instrumentales integrantes del sector público gallego, se detallará con claridad el importe de las mismas, el objeto del convenio y la persona o entidad destinataria.

$\mathrm{Ni}$ en el primer ni en el segundo anteproyecto de la ley de transparencia estatal se incluía a las encomiendas de gestión dentro de la lista de materias propias de publicidad activa sino que se hizo tras el informe del Consejo de Estado. En él se señalaba que teniendo en cuenta que una parte relevante de los servicios que se prestan a las entidades del sector público se satisfacen a través de esta figura y la oscuridad que la caracteriza, debían recogerse en la norma. En la publicación de las encomiendas de gestión se darán a conocer los siguientes datos: la información de su presupuesto, el objeto de la encomienda, las obligaciones económicas, las tarifas con arreglo a las cuales se han establecido tales obligaciones y la realización, en su caso, de subcontrataciones, con indicación de los adjudicatarios, del procedimiento de acuerdo con el cual hayan de seleccionarse y de los importes de adjudicación. Esta recomendación fue atendida prácticamente en su totalidad y el proyecto recogió las encomiendas de gestión y la información señalada entre las materias de publicidad activa, salvo las tarifas.

${ }^{23}$ C. A. AMOEDO SOUTO, "La Ley de transparencia y buen gobierno de Galicia y sus novedades en materia de contratación pública", en http://www.obcp.es/index.php/mod.opiniones/mem.detalle/id.230/relcategoria.208/relm enu.3/chk.f8e0f7c5ba834ab0329c0bc9d7dc9ace (consulta en diciembre 2017). 
A nivel autonómico, el artículo 16 de la LGT obliga a que las entidades integrantes del sector público autonómico informen sobre encomiendas de gestión y encargos a medios propios. En concreto, además de lo previsto a nivel estatal ("las encomiendas de gestión que se firmen, con indicación de su objeto, presupuesto, duración, obligaciones económicas y las subcontrataciones que se realicen con mención de los adjudicatarios, procedimiento seguido para la adjudicación e importe de la misma") se indicará anualmente, "el porcentaje de actividad realizada por el medio propio a favor de los entes de control". Se trata de datos muy relevantes para poder determinar correctamente con cierta seguridad jurídica, y controlar, aquellos instrumentos propios que resultan amparados por el Derecho Comunitario derivado al cumplir el porcentaje del $80 \%$ previsto por el art. 12 de la Directiva 2014/24/UE ${ }^{24}$.

\subsubsection{Subvenciones y ayudas públicas}

Es importante destacar que este apartado presenta un alcance general ya que es preciso publicitar no solo las subvenciones y ayudas de la Ley $38 / 2003$, general de subvenciones, sino también todas las que se reciban, incluso las no sometidas a la publicidad o no reguladas por ella, como son, por ejemplo, las recibidas por los partidos políticos de las administraciones públicas. Se indicará de todas ellas su importe, objetivo o finalidad y beneficiarios. A nivel de la Comunidad Autónoma de Galicia tendrán el mismo régimen jurídico que las subvenciones, según el artículo 17 de la LGT: a) cualquier otro acuerdo o resolución del que resulte un efecto equivalente a la obtención de ayudas directas por parte del beneficiario o beneficiaria; y b) las aportaciones monetarias realizadas por la Comunidad Autónoma a favor de las entidades locales, siempre que no estén destinadas a financiar globalmente la actividad de cada ente.

A mayores de lo previsto en la normativa básica, la ley autonómica exige que se publicite el texto íntegro de la convocatoria y las concesiones de dichas ayudas o subvenciones aunque con ciertos límites (17.3 LGT): cuando no se vulnere el honor y la intimidad personal y familiar de las personas físicas de acuerdo con lo que establece la ley orgánica de tutela de estos derechos; si los datos no estén protegidos por el secreto comercial o industrial; o siempre que no lo exijan o aconsejen razones prevalentes por la existencia de un interés público más digno de protección (que en caso de concurrir deberá ser motivado expresamente).

\subsubsection{Los presupuestos y el estado de ejecución}

Se ha afirmado con acierto que "el interés de la ciudadanía por conocer el estado de las cuentas públicas es constante y desde luego ha ido creciendo con la crisis económica" 25 . Sin duda, en la actualidad las personas han de poder acceder a la información que les permita conocer a qué se destinan los fondos públicos y los tributos que ellos pagan. La

${ }^{24}$ C. A. AMOEDO SOUTO, "La Ley de transparencia y buen gobierno de Galicia y sus novedades en materia de contratación pública", op. cit.

${ }^{25}$ C. BARRERO, E. GUICHOT y C. HORGUÉ, "Publicidad activa", op. cit., p. 182. 
obligación de contribuir a las cargas y a los impuestos tiene que ser correlativa con el derecho de estar al tanto de cómo se emplean los recursos y cuál ha sido su gestión.

La información sobre los presupuestos de las organizaciones públicas ha sido una materia sobre la que hubo acuerdo desde los primeros momentos de tramitación de la LETAI. La novedad de esta previsión del art. 8.1 d) no es precisamente la obligación de publicidad de los presupuestos y su estado de ejecución. Su publicación oficial ya estaba ya prevista. La novedad radica en el real conocimiento y comprensión de todo ello por la ciudadanía. La publicación oficial sin más de los presupuestos públicos no garantiza su entendimiento. El volumen de las partidas presupuestarias de muchas administraciones públicas $y$, sobre todo, la complejidad de los conceptos técnicos utilizados dificultan considerablemente el entendimiento de los ciudadanos en general ${ }^{26}$. Se requieren conocimientos en contabilidad o economía para distinguir los estados de ingresos y gastos. Por esta razón, la transparencia que este art. 8.1.d) LETAI proclama ha de permitir entender al común de los ciudadanos el estado de las cuentas públicas, para lo cual se alude al adjetivo "comprensible". Si ello no se logra, no servirá realmente a los objetivos por los que lucha el principio de transparencia. Particularmente, a nivel autonómico gallego, la Xunta de Galicia hará pública toda la información complementaria sobre sus presupuestos que sea remitida al Parlamento a lo largo del ejercicio, incluyendo una actualización trimestral en función de la ejecución presupuestaria, así como también la liquidación anual (art. 11.1 LGT).

\subsubsection{Cuentas anuales}

El artículo 8.1.e) LETAI prevé la publicidad de "las cuentas anuales que deban rendirse y los informes de auditoría de cuentas y de fiscalización por parte de los órganos de control externo que sobre ellos se emitan". Es fundamental para la transparencia económico-financiera que se publiquen en línea, en formatos reutilizables, las cuentas anuales. De todos modos, la doctrina esgrime críticas en este tema porque solo se incorporan a la publicidad activa los informes de fiscalización externa y no los de fiscalización o auditoría interna, que tienen una importancia cada vez mayor en el ámbito público ${ }^{27}$.

En esta línea, la disposición final tercera de la LETAI realiza una modificación en el art. 136.4 de la Ley estatal 47/2003, general presupuestaria, para exigir que "las entidades que deben aplicar los principios contables públicos, así como las restantes que no tengan obligación de publicar sus cuentas a través del Registro Mercantil, publicarán anualmente en el Boletín Oficial del Estado, el balance de situación y la cuenta de resultado económico-patrimonial, un resumen de

${ }^{26}$ C. BARRERO, E. GUICHOT y C. HORGUÉ, "Publicidad activa", op. cit., p. 183.

27 C. BARRERO, E. GUICHOT y C. HORGUÉ, "Publicidad activa", op. cit., pp. 183-184. También M. VILLORIA MENDIETA, "La publicidad activa en la ley de transparencia, acceso a la información y buen gobierno: posibilidades e insuficiencias", op. cit., pág. 40. 
los restantes estados que conforman las cuentas anuales y el informe de auditoría de cuentas". A estos efectos, la Intervención General de la Administración del Estado determinará el contenido mínimo de la información a difundir.

Las propuestas dirigidas a extender esta obligación de publicidad a cualquier entidad privada que reciba fondos públicos fueron rechazadas en la elaboración de la LETAI. Ello hubiera sido lo lógico teniendo en cuenta que se trata de un dinero público y por tanto resulta razonable que se deba aclarar a los ciudadanos el destino que ha tenido.

\subsubsection{Información referida a los altos cargos $y$ personal de designación política}

No cabe duda de que los representantes políticos deben actuar con objetividad e imparcialidad, de acuerdo al principio de legalidad y con base en principios éticos firmes. En este sentido, en nuestro ordenamiento jurídico han ido apareciendo normas para satisfacer la idea de "buen gobierno" que sirviera de prevención para conductas irregulares en la gestión de los asuntos públicos. La LETAI, en su art. 8.1.f) g) y h), incrementa la transparencia en relación con determinados gestores públicos, imponiendo la publicidad en las páginas web o sedes electrónicas de determinada información con repercusión económica: las retribuciones percibidas e indemnizaciones por abandono del cargo; las resoluciones de autorización o reconocimiento de compatibilidad para el ejercicio de actividades; y las declaraciones de bienes y de actividades de los representantes locales.

Con todo, no se explica bien por qué la obligación de publicidad activa del artículo citado no alcanza a las declaraciones de bienes y actividades de otros representantes públicos o a los altos cargos en el ámbito estatal o autonómico ${ }^{28}$. Ciertamente, la Ley estatal 5/2006, de regulación de los conflictos de intereses de los miembros del Gobierno y de los altos cargos de la Administración General del Estado, prevé que la declaraciones de actividades de los altos cargos del Estado se inscriban en un registro que es público. La disposición final segunda LETAI modifica el art. 14.4 de la citada Ley 5/2006, haciendo extensiva la publicidad a través del Boletín Oficial del Estado del contenido de las declaraciones de bienes y derechos patrimoniales de todos los altos cargos que relaciona la propia Ley $5 / 2006$, con la salvedad de que tal publicación solo requiere que sea "comprensiva de la situación patrimonial de estos altos cargos, omitiéndose aquellos datos referentes a su localización y para garantizar la privacidad y seguridad de sus titulares".

\subsubsection{Información estadística sobre el cumplimiento y calidad de los servicios públicos}

El último apartado del art. 8.1 LETAI, el i), indica que es preciso publicar la información estadística que permita valorar el grado de cumplimiento y

${ }^{28}$ C. BARRERO, E. GUICHOT y C. HORGUÉ, "Publicidad activa", op. cit., p. 190. 
la calidad de los servicios públicos, sin entrar en más detalles. Resulta realmente difícil definir a priori en qué puede concretarse esta obligación. Cada administración y organismo precisará cómo valora el cumplimiento y la calidad de sus servicios públicos. En todo caso, resulta obvio que la satisfacción de la obligación exige una investigación de suficiente calidad como para poder valorar, y no estimar, su cumplimiento ${ }^{29}$.

El art. 11 LGT resulta mucho más exhaustiva, quizás demasiado, al prever las entidades del art. 3.1 LGT deberán dar a conocer lo siguiente ${ }^{30}$ : a) la información básica sobre la financiación, con indicación de los diferentes instrumentos; b) el techo de gasto no financiero aprobado para cada ejercicio; c) los planes económico-financieros aprobados para el cumplimiento de los objetivos de estabilidad presupuestaria y sostenibilidad financiera, así como información sobre el cumplimiento de los objetivos de estabilidad presupuestaria y estabilidad financiera; d) la situación déficit/superávit público sobre producto interior bruto y por habitante; e) la deuda pública de la Administración, con indicación de su evolución, el endeudamiento por habitante, el endeudamiento relativo y el porcentaje del endeudamiento sobre el producto interior bruto; f) el periodo medio de pago a proveedores; g) el gasto por habitante y la inversión por habitante y territorializado; $h$ ) las estadísticas en materia tributaria, conforme a parámetros geográficos, poblacionales o económicos; e i) cualesquiera otras informaciones económicas y estadísticas de elaboración propia cuya difusión sea más relevante para el conocimiento general, facilitando las fuentes, notas metodológicas y modelos utilizados.

\subsubsection{Las declaraciones anuales de bienes y actividades de los representantes locales}

Como ya se mencionó antes, el art. 8.1.h) LETAI recoge la publicación de estas declaraciones, "en los términos previstos en la Ley 7/1985, de 2 de abril, Reguladora de las Bases del Régimen Local".

En el régimen local sus representantes han de realizar una declaración sobre cualquier actividad que les proporcione o pueda proporcionar ingresos económicos, así como la declaración de sus bienes patrimoniales y de la participación en sociedades de todo tipo, que tendrán que inscribirse en el Registro de Actividades y en el de Bienes Patrimoniales respectivamente, ambos de carácter público. La LETAI supone un avance importante en la materia, dado que, si se publicita en línea, de forma clara, estructurada y entendible, esto permitirá comprobar si lo que se dice en las declaraciones es cierto, lo que desincentivará la falsedad y los posibles actos corruptos ${ }^{31}$.

\footnotetext{
${ }^{29}$ M. VILLORIA MENDIETA, "La publicidad activa...", op. cit., p. 56.

30 Quedan por lo tanto fuera de esta obligación los partidos políticos, organizaciones sindicales, organizaciones empresariales y entidades privadas perceptoras de fondos públicos (art. 3.2 LGT), en la misma línea de la LETAI (art. 3 LETAI).

${ }^{31}$ M. VILLORIA MENDIETA, "La publicidad activa...", op. cit., p. 57.
} 
Aquí, de nuevo, hay que reiterar la crítica que comentábamos supra: no se entiende por qué solo se hacen públicos estos datos de los representantes locales y no también los de los diputados y senadores, cargos constitucionales y altos cargos de todo tipo.

\subsubsection{Relación de los bienes inmuebles que sean de su propiedad o sobre los que ostenten algún derecho real}

Las Administraciones Públicas publicarán la relación de "los bienes inmuebles que sean de su propiedad o sobre los que ostenten algún derecho real" (art. 8.3 LETAI). Se excluye, así, de manera injustificada la obligación de publicar todo el resto del patrimonio que poseen, esto es, no solamente los bienes inmuebles, sino asimismo los otros bienes y derechos que conforman dicho patrimonio ${ }^{32}$. Ello implica ocultar a los ciudadanos una parte muy importante del patrimonio público español, como es todo lo relacionado con los bienes muebles y derechos reales de las entidades públicas.

La LGT no incurre en esta omisión sino todo lo contrario. De este modo, se dispone en su art. 12 que el sector público autonómico ha de publicar la relación de bienes de interés cultural, sin realizar ninguna especificación de bienes muebles o inmuebles. Además, añade que también se dará a conocer el número de vehículos públicos en régimen de titularidad o arrendamiento.

\subsection{Referencia adicional a la LGT}

Ya hemos realizado varias referencias a la normativa gallega al hilo del comentario de las páginas anteriores siguiendo la estructura de la ley estatal. Ahora sólo nos limitamos a un apunte adicional.

La LGT sigue las líneas marcadas por la LETAI, ampliándolas, incluso de manera excesiva. De forma reiterada toma expresamente como punto de partida la información que debe publicarse según la normativa básica (arts. $7,9,10,11.1,12,13.1,15.1,15.2,16$, y 17.1) ${ }^{33}$, a la que añade más obligaciones. De esta forma, es más detallada tanto en las categorías en las que organiza esta publicidad activa, como en los concretos elementos de dentro de cada una de ellas. Así, de los arts. 7 a 19 recogen estas obligaciones bajo los siguientes rótulos: información institucional, organizativa y de planificación; información sobre las relaciones con la ciudadanía; información de relevancia jurídica; información en materia de personal; información económica, presupuestaria y estadística; información patrimonial; en materia de contratación pública; sobre concesión de servicios públicos; sobre convenios; sobre encomiendas de gestión y encargos a medios propios; sobre subvenciones; sobre

\footnotetext{
32 J. LIZCANO ÁLVAREZ, "La nueva Ley de transparencia: un importante desafío social", en http://www.abogacia.es/2013/12/23/la-nueva-ley-de-transparencia-un-importantedesafio-social/.

${ }^{33}$ También en otros lugares de la LGT se cita la normativa básica: arts. 6.2, 21.1, 24.1, $25.1,27.1,28.1,29.1,44.2,53,55.1,59.4$ y 60.2 .
} 
ordenación del territorio y medio ambiente; y sobre las relaciones de la Xunta con el Parlamento de Galicia.

Puede decirse que la LGT presta una especial atención a tres materias que entiende relevantes para la ciudadanía: personal, ordenación del territorio y medio ambiente, y relaciones de la Xunta con el Parlamento. A cada una de ellas les dedica un artículo de manera exclusiva. El art. 10 LGT dispone que los sujetos citados en el art. 3.1 deberán dar a conocer, entre otras cosas, la información siguiente: las relaciones de puestos de trabajo, los efectivos de personal, los permisos para la realización de funciones sindicales, las cuantías de las retribuciones, las ofertas públicas de empleo y las convocatorias para su ingreso y provisión. Asimismo, esta norma es especialmente minuciosa con los datos que deben ser difundidos de los altos cargos: biografía, trayectoria profesional, retribuciones, viajes, declaración de bienes patrimoniales y actividades profesionales e incluso resoluciones de autorización del ejercicio de actividad privada previo cese. En el art. 18 LGT, y por lo que se refiere a la ordenación del territorio y medio ambiente, se establece que deberán darse a conocer: los instrumentos de ordenación del territorio y los planes urbanísticos así como sus correspondientes modificaciones y revisiones, la información geográfica de importancia general y la medioambiental cuya publicidad exige la normativa vigente, y todo lo relativo a los convenios urbanísticos que se suscriban. Por último, el art. 19 regula las relaciones de la Xunta con el Parlamento de Galicia. El Ejecutivo autonómico informará en el Portal de transparencia y Gobierno abierto de la relación de los acuerdos aprobados en el Parlamento de Galicia que afecten a sus competencias y de aquéllos que la insten a dirigirse a otras entidades. De igual modo, a finales de año, elaborará un informe para dar a conocer el grado de cumplimiento de los acuerdos aprobados por el Parlamento en ese período.

Incluso, la LGT contempla una última previsión abierta que puede conllevar la ampliación de las obligaciones de publicidad activa: el art. 20 LGT preceptúa que los sujetos incluidos en el ámbito de aplicación de la presente ley "fomentarán la difusión de cualquier otra información pública que se considere de interés para la ciudadanía".

Como puede fácilmente comprobarse, el esfuerzo que deben realizar los distintos entes sujetos a obligaciones de transparencia resulta importante, también en el ámbito tecnológico. Siguiendo a Tejedor Bielsa se puede hablar, incluso, de que ese esfuerzo resulta inabordable para algunos de ellos, lo que exigirá en muchas ocasiones la colaboración y coordinación interadministrativa si se quiere garantizar el cumplimiento de la nueva norma. No se trata sólo de que los sujetos obligados deben adecuar sus plataformas tecnológicas a las obligaciones de publicidad activa y libre acceso, sino también de permitir que soporte de manera adecuada las exigencias de la normativa de protección de datos y, en todo caso, de generar procedimientos dinámicos de actualización ${ }^{34}$.

34 J. TEJEDOR BIELSA, "Una labor ingente: publicidad activa y libre acceso a la información activa", en http://www.administracionpublica.com/ley-transparencia/ 


\section{GARANTÍAS}

En el específico terreno de la publicidad activa, las garantías del cumplimiento de las obligaciones conectadas con la misma son escasas.

En el ámbito de la LETAI hay que citar el art. 9, rotulado "control". Este precepto no tiene el carácter de básico (disposición final octava LETAI), por lo que no resulta de aplicación a las comunidades autónomas. Así, el control se atribuye al Consejo de Transparencia y Buen Gobierno cuando se trata de la Administración General del Estado. Dicho órgano también resulta el competente para dictar resoluciones en las que se establezcan las medidas que sea necesario adoptar para el cese del incumplimiento y el inicio de las actuaciones disciplinarias que procedan. La LETAI no recoge clara y explícitamente infracciones ni sanciones a responsables y funcionarios públicos por el incumplimiento de las normas de transparencia. En lo que ahora nos atañe, el art. 9.3 LETAI se limita a remitir a la "correspondiente normativa reguladora". De este modo se afirma que "el incumplimiento reiterado de las obligaciones de publicidad activa reguladas en este capítulo tendrá la consideración de infracción grave a los efectos de aplicación a sus responsables del régimen disciplinario previsto en la correspondiente normativa reguladora". Sin duda, hubiera sido adecuado que se incluyesen de forma expresa en la LETAI diversos supuestos de infracciones y sanciones en relación con el incumplimiento de las normas recogidas tanto en lo referido a la publicidad activa como en lo relativo al derecho de acceso a la información pública. Las sanciones que se recogen se refieren a la cuestión del buen gobierno.

Algo similar sucede con la LGT, que tampoco establece régimen sancionador para la transparencia en la actividad pública (publicidad activa y derecho de acceso), limitándose tal régimen al buen gobierno, salvo lo previsto en el art. 55.2 LGT, que se extiende a todas la obligaciones de la ley, y no sólo a las de buen gobierno.

\section{EL PORTAL DE TRANSPARENCIA}

Tanto la normativa estatal como la autonómica prevén sendos portales de transparencia, a los que hay que aplicar las características que hemos visto antes al referirnos a los principios de la publicidad activa, cuando comentamos las sedes electrónica o páginas webs (subapartado 2.5 de este artículo).

De este modo, la LETAI contempla la creación y desarrollo de un Portal de Transparencia como un único punto de acceso para que el ciudadano pueda obtener toda la información disponible. El Preámbulo de la LETAI, en su parte III, le concede al Portal una elevada dimensión al entender que debe ser "un punto de encuentro y difusión". Dicho Portal, que dependerá del Ministerio de la Presidencia, no sólo incluirá la información sobre la que existe una obligación de publicidad activa, sino también "aquella cuyo acceso se solicite con mayor frecuencia" (art. 10.1 y 10.2 LETAI). Además, se establecen tres principios a los que debe responder 
este Portal: la accesibilidad, la interoperabilidad y la reutilización (art. 11 LETAI). Sobre los mismos ya reflexionamos supra, en el citado punto 2.5, donde se aludía a la normativa específica que regula los dos últimos. El Portal de Transparencia del Gobierno de España, que se abrió en diciembre de 2014, se localiza en http://transparencia.gob.es. Uno de los links de dicha web lleva a otra dirección que recopila datos abiertos para su reutilización http://datos.gob.es. Este último lugar es una iniciativa en la que colaboran todas las administraciones (estatal, autonómica, local, y también universidades).

También la LGT regula un específico portal, que denomina en su art. 29 como Portal de Transparencia y Gobierno abierto, un "punto de acceso electrónico para poner a disposición de la ciudadanía, a través de internet, la información que deba hacerse pública" (art. 29.1 LGT). Esta ley establece concretas exigencias con relación al mismo, entre ellas las siguientes: el acceso de la ciudadanía será gratuito, la información estará disponible en gallego y castellano, se permitirá la interconexión con otras direcciones electrónicas de servicios web sociales y participativos de titularidad pública, se garantizará la actualización de la información, y existirá un sistema de suscripciones que permita recibir información de los ámbitos que el ciudadano indique. También como ocurre con el Estado, se incorporará aquellas información "cuyo acceso se solicite con mayor frecuencia" (art. 29.4 LGT). Además de lo dicho, en otros lugares de la LGT se hacen previsiones adicionales. Así, la Xunta de Galicia debe publicar anualmente en el Portal el informe que aprueba la Comisión interdepartamental de Información y Evaluación (art. 5.2 LGT), la información de los contratos menores (art. 13.2 LGT), la relación de acuerdos aprobados en el Parlamento que afecten a las competencias de la Xunta y su grado de cumplimiento (ya citado, art. 19 LGT), los modelos de solicitud de información para la ciudadanía (que podrán ser enviados desde el portal, art. 26.3 LGT), las resoluciones que reconozcan la compatibilidad con actividad privada (art. 45.5 LGT), las declaraciones de las actividades y de bienes patrimoniales de altos cargos (arts. 49.1 y 49.2 LGT), y el informe que la Xunta elabora anualmente sobre los expedientes sancionadores (art. 61 LGT). También se publicarán las resoluciones del Valedor sobre las reclamaciones (art. 28.4) ${ }^{35}$, y el informe anual que este órgano presenta en el Parlamento de Galicia (art. 36 LGT). De igual forma, se prevé que exista un "portal de datos abiertos" accesible desde el Portal de Transparencia y Gobierno Abierto. En aquél se ubica el acceso al "Catálogo de información reutilizable" (art. 23.2 LGT). También tendrá un espacio para que la ciudadanía haga propuestas (art. 23.3 LGT).

Este Portal de Transparencia de la Xunta de Galicia se halla en https://transparencia.xunta.gal/ Uno de sus links lleva a la página de datos abiertos, cuya URL es http://abertos.xunta.gal/ El resto de órganos ubican su información de transparencia en una sección de su web

35 Se equivoca el legislador con esta redacción pues el órgano para resolver las reclamaciones es la Comisión de Transparencia, no el Valedor do Pobo (art. 33.3 LGT). 
institucional, como el Parlamento de Galicia, el Valedor do Pobo o el Consello de Contas.

\section{MIRADA AL FUTURO}

Comentábamos en la introducción de este trabajo que la publicidad activa, correctamente entendida, supone un cambio de paradigma y de rol en la posición del poder público con relación a la ciudadanía. La progresiva asunción de estas ideas debería favorecer la aparición de una verdadera confianza entre el poder y las personas, asumiendo aquél un papel que facilite la participación de éstas. La democracia participativa que se intenta asentar para renovar la tradicional democracia representativa exige este nuevo entendimiento del papel a jugar por los poderes públicos en el sistema políticosocial.

Además, el tema de la publicidad activa debe ser entendido en un sentido dinámico, para permitir la aparición de nuevas obligaciones que en el pasado no se vislumbraban. En este sentido también habrá que entender la citada previsión abierta del art. 20 LGT y la exigencia de colaboración entre las distintas administraciones, como dice el art. 10.3 LETAI: "La Administración General del Estado, las Administraciones de las Comunidades Autónomas y de las Ciudades de Ceuta y Melilla y las entidades que integran la Administración Local podrán adoptar otras medidas complementarias y de colaboración para el cumplimiento de las obligaciones de transparencia recogidas" en el capítulo dedicado a la publicidad activa. Esto se conecta con la necesaria actualización de la información, que es una cuestión no menor pues su incumplimiento frustra las expectativas ciudadanas. Por eso Cotino advierte que "las mayores preocupaciones en esta materia son la continuidad e interés en el cumplimiento de las obligaciones, así como la calidad y sobre todo, la actualización de la información" ${ }^{36}$.

\section{CONCLUSIONES}

La publicidad activa es uno de los elementos nucleares del principio de transparencia, dotándolo de un fuerte aspecto objetivo. Por ello, debe subrayarse su importancia y transcendencia en el conjunto de finalidades de regeneración democrática y participación ciudadana que conlleva el principio de transparencia.

Hemos visto en las páginas anteriores un elevado número de previsiones, tanto de carácter general como obligaciones concretas, básicas marcadas por el Estado y de desarrollo realizadas por la Comunidad de Galicia. En todo caso, dichas exigencias hay que interpretarlas en el contexto de la cultura de transparencia, que es la que debe mover a los responsables públicos a cumplir con estas obligaciones en el convencimiento de que están mejorando nuestra democracia y nuestro sistema de convivencia.

En definitiva, debemos defender un entendimiento dinámico y abierto de la publicidad activa, sensible a ampliaciones o reajustes en el futuro que sirvan para adaptarse a las nuevas exigencias de la ciudadanía y del

${ }^{36}$ L. COTINO, "España", en VV. AA., op. cit., p. 239. 
funcionamiento público. La doctrina debe abogar por tales planteamientos, como hemos intentado hacer en este trabajo, para procurar que todo el armazón normativo del que nos hemos dotado se aplique adecuadamente. No en vano, la información pública pertenece a la ciudadanía, no a la administración.

\section{BIBLIOGRAFÍA}

AMOEDO SOUTO, C. A., "La Ley de transparencia y buen gobierno de Galicia y sus novedades en materia de contratación pública", en http://www.obcp.es/index.php/mod.opiniones/mem.detalle/id.230/r elcategoria.208/relmenu.3/chk.f8e0f7c5ba834ab0329c0bc9d7dc9ac e.

BARRERO C., GUICHOT E. y HORGUÉ, C., "Publicidad activa", en E. GUICHOT (coord.), Transparencia, acceso a la información pública y buen gobierno. Estudio de la ley 19/2013, de 9 de diciembre, Tecnos, Madrid, 2014.

BLANE CLIMENT, M. A., La transparencia informativa de las administraciones públicas, Aranzadi, Cizur Menor, 2014.

COTINO, L., "España", en VV. AA., Transparencia e información pública, Federación Iberoamericana de Ombudsman, Madrid, 2015, pp. 231246.

FERNÁNDEZ RODRÍGUEZ, J. J. y NEIRA BARRAL, D., "El papel de las defensorías del pueblo en España en el control de la transparencia y el acceso a la información", Revista Estado, Gobierno y Gestión Pública, Universidad de Chile, núm. 27, 2016, pp. 89-116.

FERNÁNDEZ RODÍGUEZ, J. J., "La reconfiguración del derecho a la educación de las personas con discapacidad", Fundamentos. Cuadernos monográficos de teoría de la constitución e historia constitucional, Universidad de Oviedo, núm. 7, 2017, pp. 393-424.

GARCÍA MORALES, M. J., Transparencia y rendición de cuentas de las relaciones de cooperación intergubernamental en el Estado autonómico, Generalitat de Catalunya, Barcelona, 2017, p. 80.

LAFUENTE BENACHES, M. Ma, "Publicidad activa y medios propios de la Administración pública" en Revista General de Derecho Administrativo, no 45, $2017 . \quad$ En http://www.iustel.com/v2/revistas/detalle_revista.asp?id=1\&numer $0=45$

LIZCANO ÁLVAREZ, J., "La nueva Ley de transparencia: un importante desafío social", en http://www.abogacia.es/2013/12/23/la-nuevaley-de-transparencia-un-importante-desafio-social/

PIÑAR MATAS, J. L., Transparencia, acceso a la información y protección de datos, Reus, Madrid, 2014.

VALERO TORRIJOS, J., FERNÁNDEZ SALMERÓN, M. (coords.), Régimen jurídico de la transparencia del sector público, Aranzadi, Cizur Menor, 2014.

VILLORIA MENDIETA, M., "La publicidad activa en la ley de transparencia, acceso a la información y buen gobierno: posibilidades e insuficiencias". 
http://exteriors.gencat.cat/web/.content/transparencia/publicacions /gov_obert1/governobert_1_es.pdf

VILLORIA MENDIETA, M. (dir.), Buen gobierno, transparencia e integrad institucional en el gobierno local, Tecnos, Madrid, 2016.

VV. AA., Transparencia e información pública, Federación Iberoamericana de Ombudsman, Madrid, 2015.

WENCES, I., KÖLLING, M. y RAGONE, S., La Ley de Transparencia, Acceso a la Información Pública y Buen Gobierno, Centro de Estudios Políticos y Constitucionales, Madrid, 2014. 